\title{
A Comparative Evaluation of Reliability of Beta and YEN Angle in Diagnosis of Skeletal Class II Malocclusion: A Lateral Cephalometric Study
}

\author{
${ }^{1}$ Priya K Gupta, ${ }^{2}$ Girish R Karandikar, ${ }^{3}$ VK Ravindranath, ${ }^{4}$ Manish Sonawane, ${ }^{5}$ Vivek J Patni
}

\begin{abstract}
Introduction: An accurate evaluation of sagittal jaw relationship is important in orthodontic diagnosis and treatment planning. Numerous angular and linear measurements have been incorporated to assess anteroposterior jaw discrepancy between maxilla and mandible so as to reach the correct diagnosis. So the purpose of this study is to compare Beta angle and YEN angle used to measure anteroposterior dysplasia and to find which is the most reliable between them.
\end{abstract}

Materials and methods: The sample comprised 26 pretreatment lateral cephalograms of Skeletal class II patients.

Results: Descriptive analysis was performed and highly significant values were found with both Beta angle and YEN angle.

Conclusion: Beta and YEN angles are significant ones to assess the sagittal jaw relationship between maxilla and mandible.

Keywords: Beta angle, Sagittal discrepancy, YEN angle.

How to cite this article: Gupta PK, Karandikar GR, Ravindranath VK, Sonawane M, Patni VJ. A Comparative Evaluation of Reliability of Beta and YEN Angle in Diagnosis of Skeletal Class II Malocclusion: A Lateral Cephalometric Study. J Contemp Dent 2016;6(2):101-103.

\section{Source of support: Nil}

Conflict of interest: None

\section{INTRODUCTION}

One of the problems in the field of orthodontics is the evaluation of sagittal jaw relationship between maxilla and mandible. Earlier, the skeletal pattern was analyzed clinically by an overall profile view of the patient and palpation of the anterior surfaces of the basal part of the jaws with the teeth in occlusion. ${ }^{1}$ After the introduction of cephalometry, various angular and linear parameters were studied and documented. Numerous angular and linear measurements have been incorporated to assess

\footnotetext{
${ }^{1}$ Postgraduate Student, ${ }^{2}$ Professor and Head, ${ }^{3}$ Professor ${ }^{4}$ Senior Lecturer, ${ }^{5}$ Reader

${ }^{1-5}$ Department of Orthodontics, MGM Dental College and Hospital, Mumbai, Maharashtra, India
}

Corresponding Author: Priya K Gupta, Postgraduate Student Department of Orthodontics, MGM Dental College and Hospital Mumbai, Maharashtra, India, Phone: +919819909491, e-mail: priya.gupta2301@gmail.com the sagittal discrepancy between maxilla and mandible into various cephalometric analyses, which could help the clinician establish the most appropriate treatment plan.

Downs ${ }^{2}$ in 1948 introduced the A-B plane angle. A few years later, Riedel ${ }^{3}$ in 1952 introduced ANB angle and it became the most commonly used measurement since that time. However, both Down's and Riedel's methods are subject to error due to variations in the position of nasion which is not fixed during growth, and any displacement will directly affect the A-B plane angle and ANB angle.

As an alternative to ANB angle, Jacobson ${ }^{4}$ in 1975 introduced Wits' appraisal. A functional occlusal plane is drawn through the overlapping cusps of first premolars and first molars. Perpendiculars drawn to the occlusal plane are termed $\mathrm{AO}$ and $\mathrm{BO}$. The distance between the points $\mathrm{AO}$ and $\mathrm{BO}$ gives the anteroposterior relation between two jaws.

Baik and Ververidou ${ }^{5}$ introduced the Beta angle in 2004. It uses three skeletal landmarks: Points A, B, and the apparent axis to the condyle (C) to assess sagittal discrepancy. Beta angle between $27^{\circ}$ and $35^{\circ}$ indicate a class I Skeletal pattern; less than $27^{\circ}$ indicate a Skeletal class II pattern; and greater than $34^{\circ}$ indicate Skeletal class III pattern.

More recently introduced sagittal dysplasia indicator is YEN angle introduced by Neela et $\mathrm{al}^{6}$. So the purpose of this study is to compare Beta angle and YEN angle used to measure anteroposterior dysplasia and to find out which is the most reliable between them (Figs 1 to 3 ).

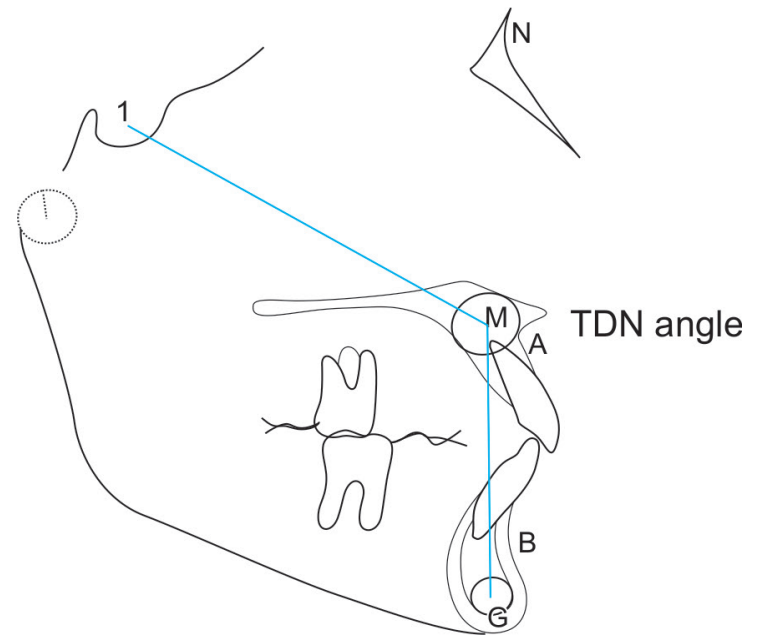

Fig. 1: YEN angle 


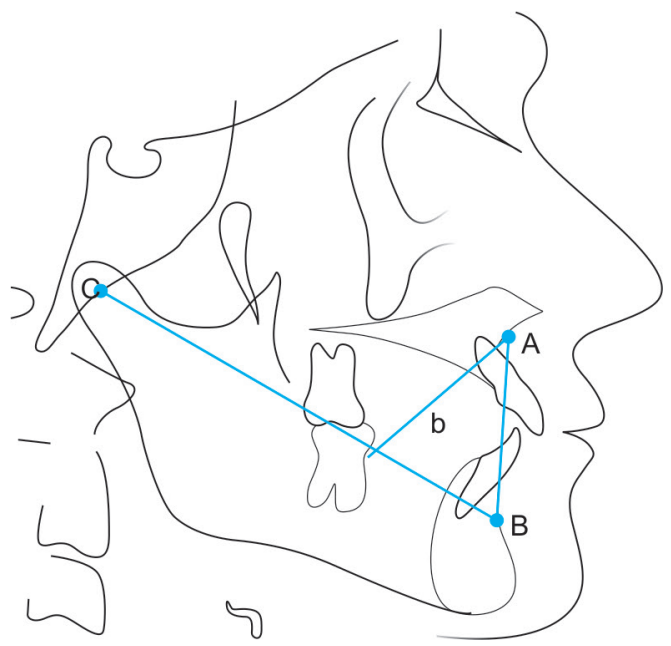

Fig. 2: Beta angle

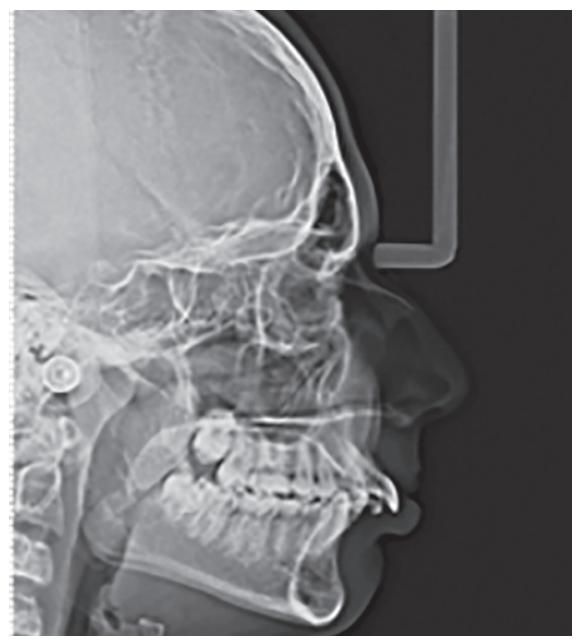

Fig. 3: Lateral cephalogram

\section{MATERIALS AND METHODS}

This study was conducted in the Department of Orthodontics and Dentofacial Orthopedics, Mahatma Gandhi Mission's Dental College, Navi Mumbai. It consisted of 26 pretreatment lateral cephalograms of 10 - to 25 -yearold individuals who had never undergone orthodontic treatment. The following inclusion criteria were taken for the class II skeletal pattern group:

- The ANB angle was above $+4^{\circ}$.

- Wits' appraisal greater than or equal to $+2 \mathrm{~mm}$.

All the lateral cephalograms were obtained in the Natural head position. These cephalograms were traced and ANB angle, Wits' appraisal, Beta angle, and YEN angle were measured to find the anteroposterior dysplasia and the most reliable among them.

\section{Statistical Analysis}

The mean, standard deviation, and the p value were calculated. Descriptive analysis was performed and highly significant differences were found with Beta angle and YEN angle (Tables 1 to 5).
Table 1: Descriptive statistics

\begin{tabular}{llllll}
\hline & $n$ & Min. & Max. & Mean & SD \\
\hline Beta angle & 26 & 16.00 & 32.00 & 23.35 & 3.76 \\
YEN angle & 26 & 88.00 & 121.00 & 111.27 & 6.25 \\
\hline
\end{tabular}

Table 2: One-sample statistics of Beta angle

\begin{tabular}{llllcl}
\hline & $n$ & Mean & $S D$ & $p$-value & SEM \\
\hline Beta angle & 26 & 23.3462 & 3.76236 & $<0.001$ & 0.73786 \\
\hline
\end{tabular}

Table 3: One-sample test of Beta angle

\begin{tabular}{|c|c|c|c|c|c|c|}
\hline & \multicolumn{6}{|c|}{ Test-value $=27$} \\
\hline & \multirow[b]{2}{*}{$t$} & \multirow[b]{2}{*}{$d f$} & \multirow{2}{*}{$\begin{array}{l}\text { Sig. } \\
\text { (2-tailed) }\end{array}$} & \multirow{2}{*}{$\begin{array}{l}\text { Mean } \\
\text { difference }\end{array}$} & \multicolumn{2}{|c|}{$\begin{array}{l}95 \% \text { confidence } \\
\text { interval of the } \\
\text { difference }\end{array}$} \\
\hline & & & & & Lower & Upper \\
\hline $\begin{array}{l}\text { Beta } \\
\text { angle }\end{array}$ & -4.952 & 25 & 0.000 & -3.65385 & -5.1735 & -2.1342 \\
\hline
\end{tabular}

Table 4: One-sample statistics of YEN angle

\begin{tabular}{llllcl}
\hline & $n$ & Mean & $S D$ & $p$-value & SEM \\
\hline YEN angle & 26 & 111.2692 & 6.25177 & $<0.001$ & 1.22607 \\
\hline
\end{tabular}

Table 5: One-sample test of YEN angle

\begin{tabular}{|c|c|c|c|c|c|c|}
\hline & \multicolumn{6}{|c|}{ Test-value $=117$} \\
\hline & \multirow[b]{2}{*}{$t$} & \multirow[b]{2}{*}{$d f$} & \multirow{2}{*}{$\begin{array}{l}\text { Sig. } \\
\text { (2-tailed) }\end{array}$} & \multirow{2}{*}{$\begin{array}{l}\text { Mean } \\
\text { difference }\end{array}$} & \multicolumn{2}{|c|}{$\begin{array}{l}95 \% \text { confidence } \\
\text { interval of the } \\
\text { difference }\end{array}$} \\
\hline & & & & & Lower & Upper \\
\hline $\begin{array}{l}\text { YEN } \\
\text { angle }\end{array}$ & -4.674 & 25 & 0.000 & -5.73077 & -8.2559 & -3.2056 \\
\hline
\end{tabular}

\section{DISCUSSION}

Cephalometrics includes measurement, description, and appraisal of dentofacial growth and changes in the skull by measuring certain planes, lines, and angles between anthropometric landmarks and points specified by orthodontics. ${ }^{7}$ A method of maxillomandibular assessment that provides accurate data on this relationship at an early age would be highly desirable. ${ }^{8}$ The ANB angle is affected by various factors because of which it can often be misleading. It has been suggested that although the apical base relationships were constant in all conditions, the ANB angle became either small or large and thus such a measurement was not reliable. ${ }^{9,10}$

Moore et $\mathrm{al}^{11}$ and Ishikawa et $\mathrm{al}^{12}$ who stated that Wits' appraisal although not affected by landmarks or jaw rotations, it still has the problem of correctly identifying the functional occlusal plane, which can sometimes be impossible, especially in mixed dentition. Our study shows that the values of Beta angle were statistically significant $(\mathrm{p}<0.001)$. This is also supported by Baik and Ververidou ${ }^{5}$ who stated that Beta angle does not depend on cranial landmarks or the functional occlusal plane and remains relatively stable even when the jaws are rotated. 


\begin{abstract}
Also, the advantage of Beta angle is that it can be used in consecutive comparisons as it reflects true changes of the sagittal relationship of the jaws, which might be due to multiple reasons. But it uses point A and B, which changes with orthodontic treatment and growth. Our study shows that the values of YEN angle were statistically significant $(p<0.001)$. This is also supported by Neela et $\mathrm{al}^{6}$ who stated that YEN angle depends on stable points, S-midpoint of sella turcica, M-midpoint of pre-maxilla, and G-center of largest circle that is tangent to the internal inferior, anterior, and posterior surfaces of the mandibular symphysis, and so it is not influenced by growth changes and can easily be used in mixed dentition. But, since it measures an angle between line SM and MG, rotation of jaw because of growth or orthodontic treatment can mask true basal dysplasia, similar to ANB angle.
\end{abstract}

\section{CONCLUSION}

It was concluded from the present study that Beta and YEN angles are statistically significant ones to assess the sagittal jaw relationship between maxilla and mandible. Since both the angles in the study have statistically significant correlation, it is recommended that instead of relying on one single parameter, others also should be checked and correlated with clinical findings for a given case.

\section{REFERENCES}

1. Doshi JR, Trivedi K, Shyagali T. Predictability of yen angle \& appraisal of various cephalometric parameters in the assessment of sagittal relationship between maxilla and mandible in angle's class II malocclusion. PJSR 2012 Jan;5(1):1-8.

2. Downs WB. Variations in facial relationships: their significance in treatment and prognosis. Am J Orthod 1948 Oct;34(10):812-823.

3. Riedel RA. The relation of maxillary structures to cranium in malocclusion and in normal occlusion. Angle Orthod 1952 Jul;22(3):142-145.

4. Jacobson A. The "Wits" appraisal of jaw disharmony. Am J Orthod 1975 Feb;67(2):125-138.

5. Baik CY, Ververidou M. A new approach of assessing sagittal discrepancies: the Beta angle. Am J Orthod Dentofacial Orthop 2004 Jul;126(1):100-105.

6. Neela PK, Mascarenhas R, Husain A. A new sagittal dysplasia indicator: the Yen angle. World J Orthod 2009 Summer;10(2): 147-151.

7. Shah AR, Karandikar G, Ravindranath VK, Sonawane M. A comparative study of reliability of manual and digital lateral cephalometric tracing. J Contemp Dent 2016;6(1): 15-18.

8. Nanda R, Merrill RM. Cephalometric assessment of sagittal relationship between maxilla and mandible. Am J Orthod Dentofacial Orthop 1994 Apr;105(4):328-344.

9. Freeman RS. Adjusting A-N-B angles to reflect the effect of maxillary position. Angle Orthod 1981 Apr;51(2):162-171.

10. Chang HP. Assessment of anteroposterior jaw relationship: Am J Orthod Dentofacial Orthop 1987 Aug;92(2):117-122.

11. Moore RN, DuBois LM, Boice PA, Igel KA. The accuracy of measuring condylion location. Am J Orthod Dentofacial Orthop 1989 Apr;95(4):344-347.

12. Ishikawa H, Nakamura S, Hiroshi I, Kitazawa S. Seven parameters describing anteroposterior jaw relationships: postpubertal prediction accuracy and interchangeability. Am J Orthod Dentofacial Orthop 2000 Jun;117(6):714-720. 